\title{
Síndrome do abscesso pituitário em bezerros associada ao uso de tabuleta nasal para desmame interrompido ${ }^{1}$
}

\author{
Alexandre P. Loretti ${ }^{2}$, Marcia R. S. Ilha ${ }^{3}$, Gabriela Riet-Correa ${ }^{4}$, David Driemeier ${ }^{2}$, \\ Edson M. Colodel $^{5}$ e Claudio S. L. Barros ${ }^{6}$
}

\begin{abstract}
Loretti A. P., Ilha M. R. S., Riet-Correa G., Driemeier D., Colodel E. M. \& Barros C. S. L. 2002. [Pituitary abscess syndrome in calves following injury of the nasal septum by a plastic device used to prevent suckling . . Síndrome do abscesso pituitário em bezerros associada ao uso de tabuleta nasal para desmame interrompido. Pesquisa Veterinária Brasileira 23(1):39-46. Depto Patologia, Universidade Federal de Santa Maria, Santa Maria, RS 97105900, Brazil.E-mail: claudioslbarros@uol.com.br

Outbreaks and sporadic cases of the pituitary abscess syndrome are described in calves in the state of Rio Grande do Sul, southern Brazil. The disease occurred in eight beef cattle farms in the municipalities of Cachoeira do Sul, Lavras do Sul, Bagé, Osório and Vila Nova do Sul, from 1998 to 2002 . Thirty-five (1.4\%) out of 2,438 calves with 3-12 months of age were affected and $24(0.98 \%)$ died. A nasal plastic device to prevent suckling had been used in all the affected calves. Clinical signs consisted of nasal discharge, depression, hyperthermia, ataxia, circling, head tilt and hypermetria, exophtalmos, dysphagia, partial mandibular paralysis, prolapse of the tongue, difficulty in chewing, drooling and in some cases blindness accompanied or not by aqueous flare, prolapse of the ocular globe and corneal opacity. In the terminal stages of the disease, there was lateral recumbency, opisthotonus and coma. The main necropsy findings included single large hypophyseal or para-hypophyseal abscesses. Those space-occupying lesions dorsally compressed the brain stem and the cranial nerves adjacent to the hypophysis. In some cases, there was also osteomyelitis of the basisphenoid bone, single or multiple brain abscesses and leptomeningitis affecting the ventral surface of the brain stem and cervical spinal cord. In a few cases, necrotizing or abscedative rhinitis associated with nose device injury was observed. Histologically, those abscesses consisted mainly of neutrophils admixed with cellular debris surrounded by numerous mononuclear cells and a fibrous capsule. Fibrino-suppurative meningitis affecting the leptomeninges of the cerebellum, brain stem and cervical spinal cord was also observed. In some cases, purulent inflammation extended into the hypophyseal parenchyma. Arcanobacterium (Actinomyces) pyogenes was isolated from the abscesses. The diagnosis of pituitary abscess syndrome was based on epidemiological data, clinical signs, necropsy findings, histological alterations and bacterial cultures.
\end{abstract}

INDEX TERMS: Abscess, pituitary, rete mirabile, nose device, diseases of cattle, pathology, central nervous system.

\footnotetext{
${ }^{1}$ Aceito para publicação em 26 de fevereiro de 2003.

${ }^{2}$ Depto Patologia Clínica Veterinária, Fac. Veterinária, Universidade Federal do Rio Grande do Sul (UFRGS), Cx. Postal 15094, Porto Alegre, RS 91540000 .

${ }^{3}$ Depto Medicina Veterinária Preventiva, Centro de Ciências Agrárias, Universidade Estadual de Londrina (UEL), Campus Universitário, Cx. Postal 6001, Londrina, PR 86051-990.
}

\footnotetext{
${ }^{4}$ Faculdade de Veterinária, Universidade Federal de Goiás (UFG), Campus Avançado de Jataí, Jataí, GO 75800-000.

${ }^{5}$ Depto Clínica Médica Veterinária, Faculdade de Agronomia e Medicina Veterinária, Fundação Universidade Federal de Mato Grosso (FUFMT), Av. Fernando Correia da Costa, Coxipó, Cuiabá, MT 78010-900.

${ }^{6}$ Depto Patologia, Universidade Federal de Santa Maria (UFSM), Santa Maria, RS 97105-900, Brasil. Autor para correspondência, e-mail: claudioslbarros@uol.com.br
} 
RESUMO.- Descrevem-se surtos e casos esporádicos de síndrome do abscesso pituitário em bovinos no Estado do Rio Grande do Sul. A doença ocorreu em 8 propriedades de gado de corte, nos municípios de Cachoeira do Sul, Lavras do Sul, Bagé, Osório e Vila Nova do Sul, no período de 1998 a 2002. De um total de 2.438 bezerros submetidos ao desmame interrompido com o uso da tabuleta nasal, aproximadamente $35(1,4 \%)$ animais adoeceram e $24(0,98 \%)$ morreram. A idade dos bezerros afetados variava entre 3 e 12 meses. Os animais doentes apresentavam corrimento nasal, depressão, febre, incoordenação motora, andar em círculos, desvio lateral da cabeça, hipermetria, exoftalmia, disfagia, mandíbula caída, protusão lingual, dificuldade de mastigação e sialorréia. Em alguns casos, observou-se também cegueira, acompanhada ou não de turvação dos humores do globo ocular, exoftalmia e opacidade da córnea. Nas fases terminais, ocorriam decúbito lateral, convulsões, nistagmo, opistótono, coma e morte. Os principais achados de necropsia consistiam em abscessos únicos pituitários ou parapituitários que comprimiam dorsalmente o tronco encefálico e nervos cranianos próximos à pituitária. Em alguns casos, havia osteomielite envolvendo o osso baso-esfenóide com a formação de abscessos na substância encefálica, leptomeningite na superfície ventral do encéfalo e medula espinhal cervical e rinite necrosante ou abscedativa associada às lesões traumáticas provocadas pela colocação da tabuleta nasal. Histologicamente, os abscessos correspondiam a grandes agregados de neutrófilos e restos celulares circundados por células mononucleares e proliferação de tecido conjuntivo. Meningite fibrinopurulenta nas leptomeninges do cerebelo, tronco encefálico e medula espinhal cervical também foi observada. Em alguns casos, a inflamação purulenta se estendia para o parênquima da pituitária. Arcanobacterium (Actinomyces) pyogenes foi isolado dos abscessos. O diagnóstico de síndrome do abscesso pituitário foi baseado nos dados epidemiológicos, sinais clínicos, achados macroscópicos, histológicos e microbiológicos.

TERMOS DE INDEXAÇÃO: Abscesso, pituitária, rete mirabile, tabuleta nasal, doenças de bovinos, patologia, sistema nervoso central.

\section{INTRODUÇ̃̃O}

Uma doença neurológica conhecida como síndrome do abscesso pituitário (SAP) ou empiema basilar tem sido descrita em bovinos (Moriwaki et al. 1973, Perdrizet \& Dinsmore 1986, Paredes et al. 1996, Fernandes et al. 2000), caprinos, ovinos (Perdrizet \& Dinsmore 1986) e eqüinos (Reilly et al. 1994). Essa enfermidade é caracterizada por formação de abscessos no complexo vascular sobre o osso baso-esfenóide, que podem, por extensão, afetar a pituitária ou estruturas vizinhas, incluindo a base do encéfalo, e por desenvolvimento de meningite supurativa, localizada preferencialmente na face ventral do encéfalo e assoalho da cavidade craniana (Moriwaki et al. 1973, Perdrizet \& Dinsmore 1986, Paredes et al. 1996, Fernandes et al. 2000). Os abscessos pituitários podem ocorrer a partir da disseminação hematógena de processos supurativos que têm origem em diferentes locais do corpo, em especial a cabeça, como sinusites, rinites e lesões dentárias (Perdrizet \& Dinsmore 1986, Reilly et al. 1994) ou por extensão direta de lesões purulentas localizadas na cabeça, como otite interna e, no caso de eqüinos, inflamação das bolsas guturais (Perdrizet \& Dinsmore 1986, Collet \& Bath 1994, Radostits et al. 1994, Reilly et al. 1994). A SAP também tem sido associada à rinite traumática séptica causada pela colocação de argolas de metal no focinho de bovinos adultos e jovens (Moriwaki et al. 1973, Smith 2002) e ao uso de tabuletas nasais para desmame interrompido em bezerros (Paredes et al. 1996, Fernandes et al. 2000). Arcanobacterium (Corynebacterium, Actinomyces) pyogenes é a bactéria mais frequientemente isolada dessas lesões abscedativas (Moriwaki et al. 1973, Perdrizet \& Dinsmore 1986, Paredes et al. 1996, Fernandes et al. 2000). Outras bactérias tais como Streptococcus spp, Pasteurella spp, Acinetobacter sp, Fusobacterium necrophorum e Pseudomonas sp. também já foram cultivadas desses abscessos (Perdrizet \& Dinsmore 1986).

A duração do quadro clínico da SAP varia de alguns dias a cerca de 6 semanas (Moriwaki et al. 1973, Perdrizet \& Dinsmore 1986). 0 início dos sinais clínicos pode variar de 5 dias a até 1 mês após rinite traumática induzida pelo uso de argolas de metal ou tabuleta nasal para desmame (Moriwaki et al. 1973, Paredes et al. 1996) ou de 1 a 3 meses após infecção em outros locais do corpo (Perdrizet \& Dinsmore 1986).

Os sinais clínicos da SAP incluem sinais neurológicos relacionados a lesões no tronco encefálico ou associados a déficits de nervos cranianos (Moriwaki et al. 1973, Perdrizet \& Dinsmore 1986, Paredes et al. 1996, Fernandes et al. 2000). Esses sinais clínicos ocorrem devido ao crescimento expansivo e compressão causada pelo abscesso ou pela extensão do processo inflamatório supurativo para os tecidos circunjacentes como por exemplo a base do encéfalo e meninges. Os sinais clínicos descritos na SAP são consistentes com lesões que afetam os nervos cranianos adjacentes à pituitária e ao complexo vascular sobre o osso baso-esfenóide tais como os nervos oculomotor, troclear, trigêmeo, abdutor e facial (De Lahunta 1977, Mayhew 1989). Nestes casos geralmente estão envolvidos principalmente os nervos trigêmeo e o abdutor (Fernandes et al. 2000).

Recentemente, surtos de SAP associados ao uso de tabuletas nasais para desmame interrompido foram descritos em bezerros no Chile (Paredes et al. 1996) e no Brasil (Schild et al. 1996, Fernandes et al. 2000). A colocação de tabuleta plástica no septo nasal para o desmame interrompido de bezerros tem como objetivo o retorno do cio da vaca pela interrupção da lactação. Usualmente, a tabuleta nasal pode ser mantida por um período de até 15 dias, após o qual é retirada, permitindo que os bezerros voltem a mamar. $\mathrm{O}$ método de desmame interrompido começou a ser utilizado em bovinos no Rio Grande do Sul no final da década de 70 (Rosa \& Real 1976/7), e sua incorporação no manejo da bovinocultura de corte extensiva na Região Sul do Brasil tem aumentado progressivamente desde então. Embora outros métodos para a indução do cio da vaca estejam atualmente sendo empregados, o uso da tabuleta nasal nos bezerros ainda é bastante utilizado no Rio Grande do Sul. Essa prática apresenta risco potencial para o desenvol- 
vimento de SAP. A dimensão dos riscos e dos prejuízos que esse procedimento pode trazer não é ainda completamente conhecida por proprietários e veterinários de campo. É necessário que se conheçam os dados epidemiológicos, clínicos e patológicos dessa condição para que se possa estabelecer o diagnóstico dessa enfermidade de modo a estabelecer medidas terapêuticas adequadas e métodos eficientes para o controle e profilaxia da enfermidade.

Com o objetivo de informar profissionais veterinários e criadores a respeito de alguns aspectos importantes dessa enfermidade, são apresentados dados colhidos em surtos ocorridos em bezerros de oito propriedades rurais do Rio Grande do Sul.

\section{MATERIAL E MÉTODOS}

Dados referentes à epidemiologia e aos sinais clínicos foram fornecidos pelos proprietários e veterinários de oito propriedades de bovinocultura de corte ou através de visitas a essas propriedades. Foram recebidas nos laboratórios de patologia da UFSM e da UFRGS cinco cabeças de bezerros afetados e foram realizadas necropsias de seis outros bezerros com sinais clínicos da enfermidade. Em todos os casos, após a retirada do encéfalo, fragmentos da pituitária, de porções adjacentes ao encéfalo e da medula espinhal cervical foram coletados e fixados em formol a $10 \%$ para histologia. Foram também coletados fragmentos da mucosa nasal e pulmões de um dos animais para exame histopatológico. Em dois casos, as cabeças foram serradas num plano médio-sagital e fragmentos do osso baso-esfenóide e o abscesso situado sobre esse osso foram colhidos. Os fragmentos ósseos, após fixação em formol a $10 \%$, foram descalcificados em ácido fórmico e então processados rotineiramente para histologia. Fragmentos frescos dos abscessos pituitários de três animais afetados foram semeados em ágar sangue a $10 \%$ e incubados a $37^{\circ} \mathrm{C}$ por 24 horas para isolamento e identificação bioquímica das bactérias.

\section{RESULTADOS}

Dados epidemiológicos. A doença foi observada na forma de surtos ou de casos esporádicos em oito propriedades de criação extensiva de gado de corte nos municípios gaúchos de Cachoeira do Sul, Lavras do Sul, Bagé, Osório e Vila Nova do Sul, durante o período de 1998 a 2002. De um total de 2.438 bezerros submetidos ao desmame interrompido com o uso da tabuleta nasal (Fig. 1), aproximadamente $35(1,4 \%)$ animais adoeceram e $24(0,98 \%)$ morreram. A idade dos bezerros afetados variava de 3 a 12 meses. Nesses casos, a tabuleta nasal foi utilizada por um período de 3 a 7 dias. 0 proprietário de quatro fazendas localizadas nos municípios de Lavras do Sul e Bagé informou que já vinha utilizando a tabuleta nasal em seus bezerros há 15 anos. Entretanto, casos da doença associados ao emprego desse dispositivo foram observados somente nos últimos 2 anos.

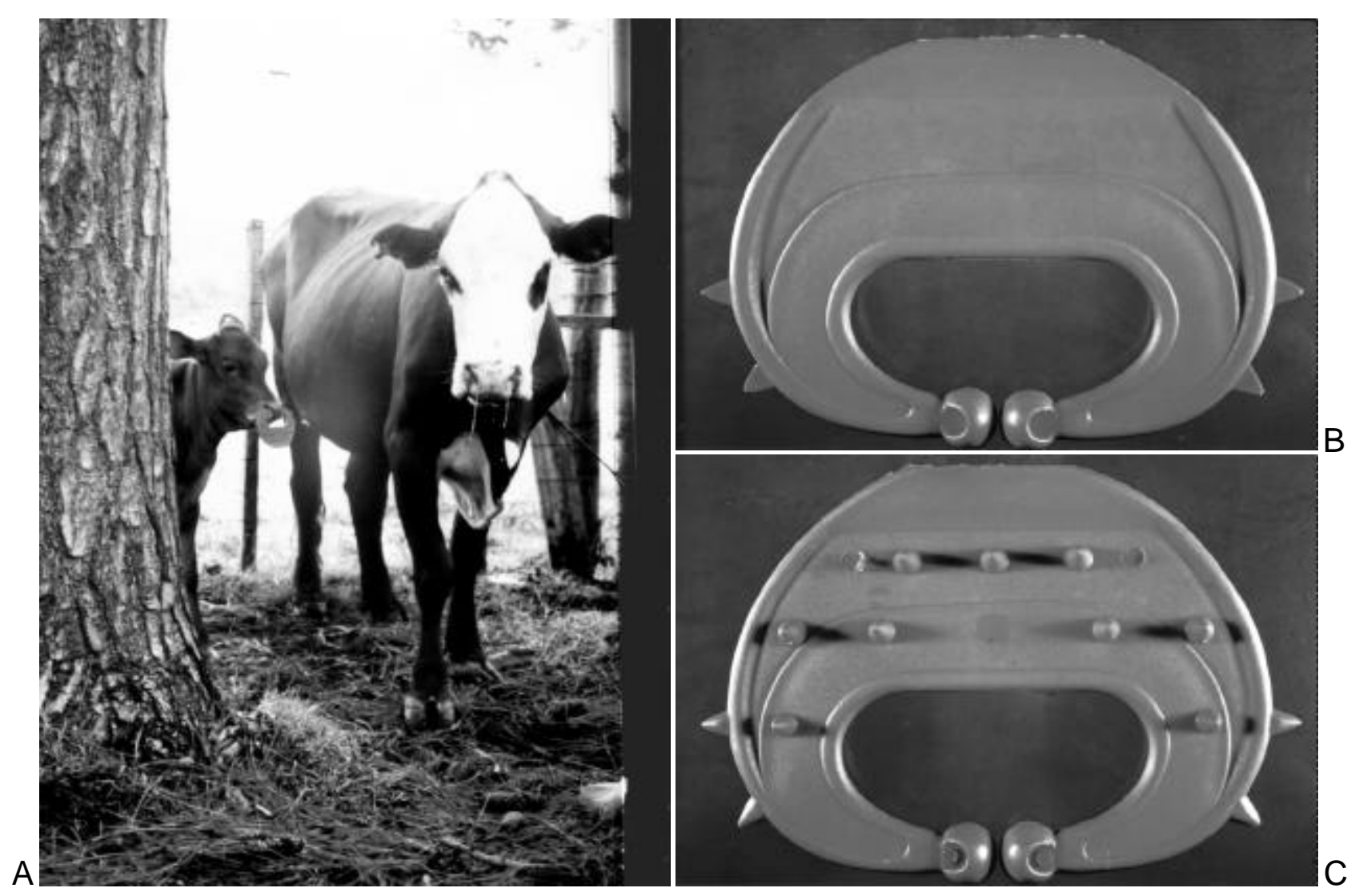

Fig. 1. (A) Bezerro com a tabuleta de plástico usada para desmame interrompido. (B) Face da tabuleta que fica voltada para o focinho do bezerro. (C) Aspecto da tabuleta que entra em contato com o úbere da vaca. Observe as projeções pontiagudas que causam desconforto à vaca quando o bezerro tenta mamar. 
Sinais clínicos. Em alguns bezerros foi observada inquietação logo após a colocação da tabuleta nasal. Os primeiros sinais clínicos foram observados cerca de 12 a 60 dias após a colocação da tabuleta nasal. $O$ curso clínico da enfermidade variou de alguns dias a 3 meses. Os bezerros afetados apresentavam corrimento nasal, depressão, febre, incoordenação motora, andar em círculos, desvio lateral da cabeça, hipermetria e exoftalmia. Disfagia, mandíbula caída, prolapso de língua, dificuldade de mastigação e sialorréia foram sinais clínicos frequientemente observados. Em alguns casos, observou-se também cegueira acompanhada ou não de turvação dos humores do globo ocular e de exoftalmia e opacidade da córnea. Nas fases terminais ocorriam decúbito lateral, convulsões, nistagmo, opistótono (Fig. 2), coma e morte. Nem todos esses sinais clínicos eram observados no mesmo animal e a intensidade desses sinais era, também, variável. Treze bezerros tratados com antibiótico apresentaram melhora no quadro clínico. Entretanto, os sinais clínicos em dois des-

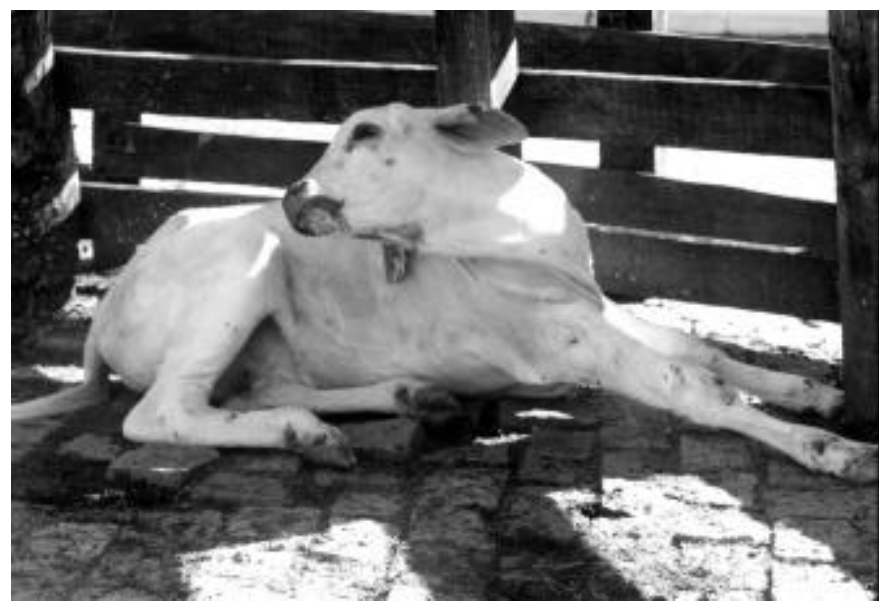

Fig. 2. Bezerro de 6 meses afetado por abscesso de pituitária, mostrando opistótono.

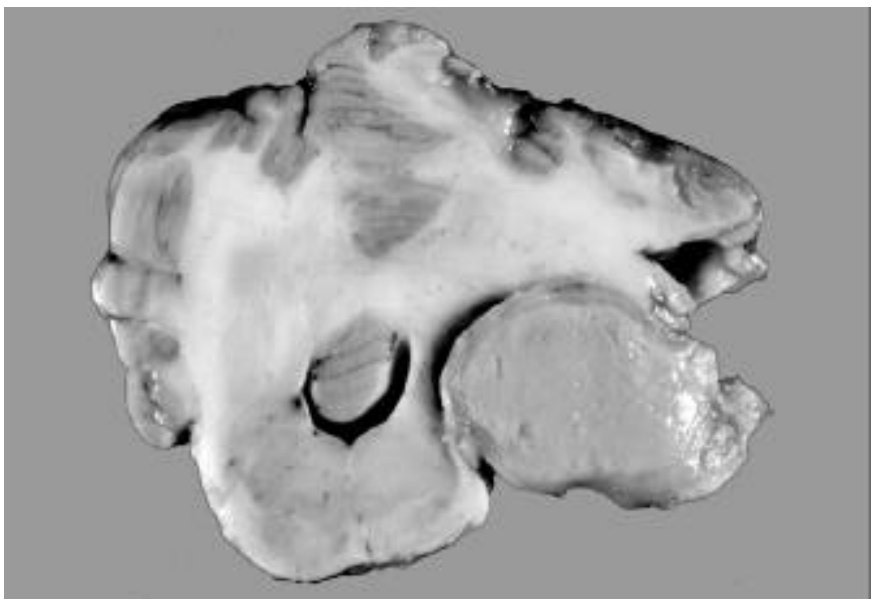

Fig. 3. A extensão de um abscesso de pituitária (seta) em um bezerro comprime o tronco encefálico (ponte, pedúnculos cerebelares) e cerebelo do lado direito. ses bezerros recidivaram diversas vezes até ocorrer a morte dos animais. Com relação aos demais animais tratados e que aparentemente se recuperaram, não foram obtidas informações a respeito de recidiva dos sinais clínicos e seqüielas neurológicas.

Achados de necropsia . Os principais achados de necropsia consistiam em um único abscesso no assoalho da cavidade craniana, de localização parapituitária ou situado no parênquima da pituitária comprimindo dorsalmente o tronco encefálico (Fig. 3), acompanhado ou não de osteomielite envolvendo o osso baso-esfenóide. As leptomeninges sobre o tronco encefálico, cerebelo e medula espinhal cervical estavam amareladas ou esbranquiçadas e opacas e levemente espessadas, principalmente sobre a medula espinhal cervical. A dura-máter sobre o osso baso-esfenóide estava espessada, amarelada, elevada e protruía na cavidade craniana. Em todos os casos observou-se um abscesso com cerca de 3 a $5 \mathrm{~cm}$ de diâmetro sobre o osso baso-esfenóide, na região da sela túrcica (Fig. 4). 0 abscesso geralmente envolvia o complexo vascular sobre o osso baso-esfenóide (seio cavernoso e rete mirabile), nervos cranianos adjacentes, principalmente os nervos oculomotor, trigêmeo e abducente, e a pituitária. Em alguns casos, a pituitária localizava-se no centro do abscesso mas a arquitetura da glândula estava preservada ou o abscesso localizava-se lateralmente à glândula pituitária (Fig. 5). Em alguns casos, cortes transversais do osso baso-esfenóide revelaram osteomielite purulenta devido à extensão do processo iniciado na região da sela túrcica e se estendia ventralmente. Em um dos casos havia também extensão do processo inflamatório supurativo dorsalmente afetando a base do encéfalo com a formação de múltiplos abscessos de até 1,5 $\mathrm{cm}$ de diâmetro localizados no parênquima encefálico da região do tálamo e hipotálamo (Fig. 6). Em três dos animais necropsiados observou-se rinite necrosante ou abscedativa multifocal. Em um desses bezerros com rinite, o lado direito da face estava aumentado de volume desde o canto medial

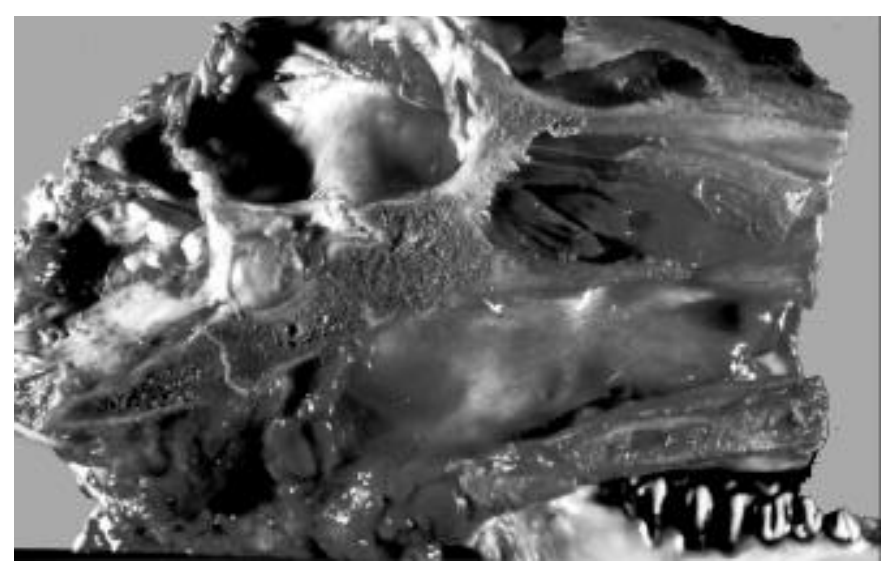

Fig. 4. Corte sagital do crânio de bezerro afetado por abscesso de pituitária. Um abscesso de cerca $3 \mathrm{~cm}$ de diâmetro (seta) pode ser observado sobre o osso baso-esfenóide na região da sela túrcica. 


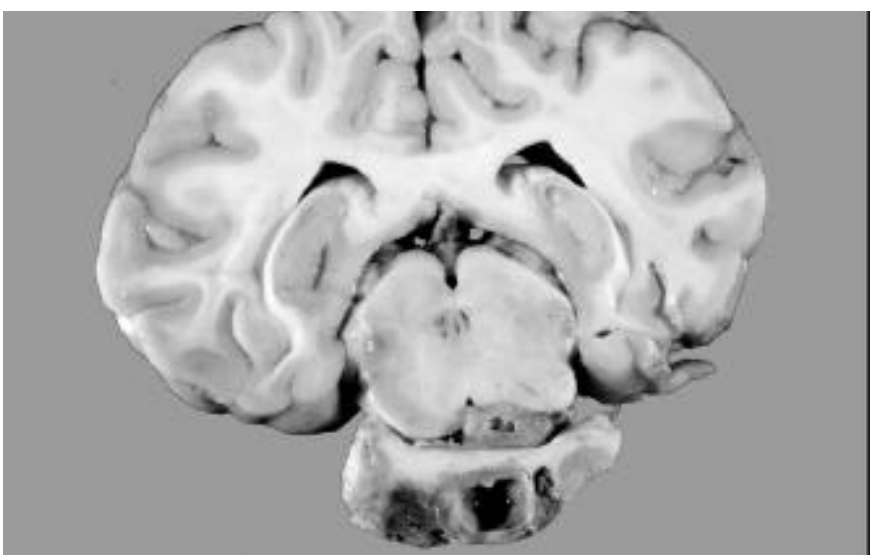

Fig. 5. Corte transversal do encéfalo de bezerro afetado pela síndrome de abscesso de pituitária. Nesse caso, pode-se observar um abscesso (seta) localizado látero-dorsalmente à glândula pituitária e comprimindo os pedúnculos cerebrais (crus cerebri) no lado direito do mesencéfalo.

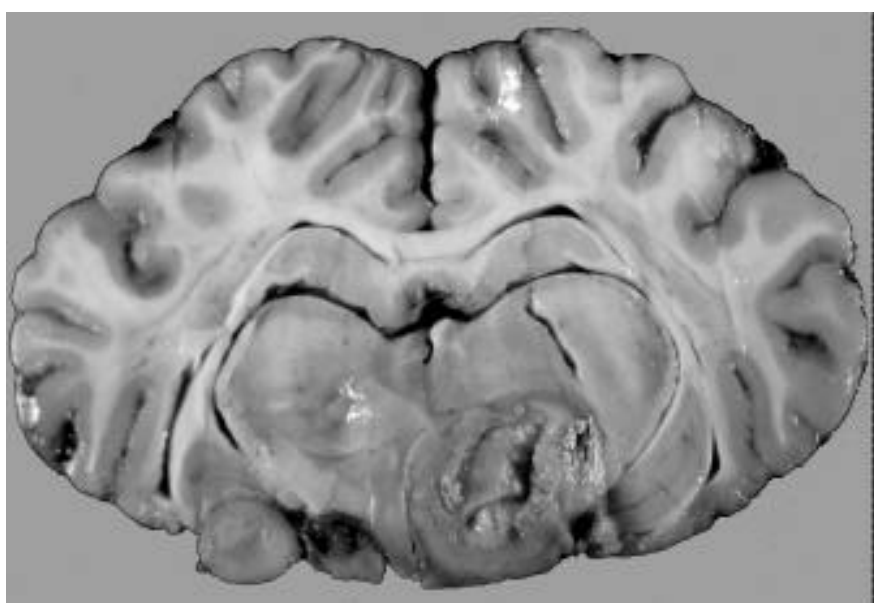

Figura 6. Corte transversal do encéfalo de bezerro afetado pela síndrome de abscesso de pituitária. Nesse caso havia extensão do processo inflamatório supurativo dorsalmente afetando a base do encéfalo. Observe um abscesso maior de $1,5 \mathrm{~cm}$ de diâmetro no parênquima encefálico no lado direito do tálamo (seta). Um abscesso menor pode ser observado do lado esquerdo sobre o hipocampo (pontas de seta).

do olho até o focinho. No tecido subcutâneo dessa região havia um trajeto fistuloso com exsudato purulento estendendo-se até o osso nasal. Na mucosa da cavidade nasal e das conchas nasais observavam-se múltiplos abscessos de até 1 $\mathrm{cm}$ de diâmetro. No segundo bezerro com rinite, havia úlceras com cerca de $2 \mathrm{~cm}$ de diâmetro na porção anterior da cavidade nasal, simétricas e bilaterais, recobertas por exsudato fibrinonecrótico. No terceiro caso apenas um abscesso de alguns milímetros de diâmetro foi observado na concha nasal média de uma das cavidades nasais. Em um único animal, lesões abscedativas foram observadas em outros órgãos além da cavidade nasal e assoalho da cavidade craniana. Nesse caso havia múltiplos abscessos, de até $4 \mathrm{~cm}$ de diâmetro, de distribuição aleatória no parênquima pulmonar, associados a pleurite fibrinosa e aderências entre as pleuras costal e visceral.

Achados histológicos. Microscopicamente, os abscessos correspondiam a grandes agregados de neutrófilos e restos celulares, rodeados por células mononucleares e proliferação de tecido conjuntivo. Em alguns casos havia focos de mineralização do tecido necrótico e colônias bacterianas intralesionais. Observaram-se também, em alguns animais, lesões abscedativas que se estendiam para o parênquima da pituitária e consistiam em áreas multifocais de necrose acompanhadas de infiltração de células inflamatórias, principalmente neutrófilos. Outras alterações histopatológicas incluíam leptominingite fibrinopurulenta no cerebelo, tronco encefálico e medula espinhal cervical, caracterizada por edema, deposição de fibrina e intenso infiltrado neutrocitário. No encéfalo adjacente às meninges foram observadas áreas de malácia, focos de hemorragia e edema e manguitos perivasculares formados por células mononucleares e neutrófilos. Os abscessos da cavidade nasal, conchas nasais e parênquima pulmonar eram histologicamente semelhantes aos observados na região da pituitária.

Bacteriologia. Arcanobacterium (Actinomyces) pyogenes foi isolado nos três casos em que fragmentos dos abscessos pituitários foram submetidos à cultura bacteriana.

\section{DISCUS SÃO}

Nos casos de síndrome do abscesso pituitário (SAP) aqui descritos, todos os bezerros tinham sido submetidos previamente ao desmame interrompido através da tabuleta nasal. Os sinais clínicos neurológicos, principalmente os de déficit dos nervos cranianos, os achados de necropsias, as lesões histológicas e o isolamento de Arcanobacterium (Actinomyces) pyogenes sugerem fortemente que os casos de SAP aqui relatados são secundários à rinite bacteriana, iniciada pelo traumatismo produzido pela tabuleta nasal. O quadro clínico-patológico observado é semelhante aos descritos previamente por outros autores (Moriwaki et al. 1973, Paredes et al. 1996, Fernandes et al. 2000).

Arcanobacterium pyogenes é uma bactéria comensal das superfícies mucosas de animais saudáveis, incluindo a mucosa do trato respiratório (Collet \& Bath 1994). Nos surtos de SAP associados à rinite traumática, essa bactéria tem sido consistentemente isolada (Moriwaki et al. 1973, Paredes et al. 1996, Fernandes et al. 2000). Sugere-se que as lesões traumáticas produzidas no septo nasal pelo uso da tabuleta facilitam a entrada desse microrganismo na mucosa nasal e a chegada desse agente, através da circulação sangǘnea ou linfática, até a pituitária, levando à formação de abscessos naquela região.

Embora a patogenia específica da SAP ainda não esteja totalmente esclarecida, hipóteses têm sido criadas para explicar a formação desses abscessos com base na localização 
da glândula pituitária, nas circulações linfática e sangüínea da região pituitária e nos achados anatomo-patológicos. Em geral, existem quatro rotas para a chegada de um agente infeccioso ao sistema nervoso central: (1) infecção centrípeta via nervo periférico; (2) através de lesões penetrantes diretas; (3) por extensão de uma lesão supurativa adjacente; e (4) através da circulação venosa, arterial ou linfática (Perdrizet \& Dinsmore 1986, Radostits et al. 1994). A infecção neurógena pelos nervos periféricos é improvável nestes casos e nos demais descritos na literatura, uma vez que os agentes infecciosos comumente isolados das lesões inflamatórias não têm capacidade de migração neural. A segunda rota possível, através de lesões penetrantes, é, também, pouco provável de estar envolvida na patogênese destas lesões abscedativas, uma vez que a pituitária se situa em um local bem protegido pelas estruturas ósseas adjacentes, na base do encéfalo. Extensão direta a partir de uma infecção na cabeça pode ser o mecanismo patogenético envolvido em alguns casos de SAP descritos na literatura (Perdrizet \& Dinsmore 1986, Reilly et al. 1994). A infecção pode, também, ocorrer por via linfática. Embora não existam vasos linfáticos no encéfalo e meninges, em certas espécies de animais há comunicação entre o sistema linfático e o fluido cerebroespinhal, particularmente na área da mucosa nasal e placa cribiforme (Perdrizet \& Dinsmore 1986, Radostits et al. 1994). Apesar disso, essa hipótese é pouco convincente, pois os abscessos ocorrem primariamente na pituitária e seus arredores. Portanto, acredita-se que os casos de SAP associados à rinite traumática estão provavelmente relacionados à disseminação bacteriana hematógena a partir da lesão traumática na porção rostral das cavidades nasais na região do septo nasal.

A glândula pituitária é circundada por um complexo sistema vascular formado por veias do seio cavernoso e artérias da rete mirabile epidural rostral (Zguigal \& Ghoshal 1991). Em ruminantes, a rete mirabile epidural rostral ou rede carotídea está situada intracranialmente no interior do seio cavernoso, na base do encéfalo. $O$ seio cavernoso pertence ao sistema basilar ou sistema ventral de seios durais e situa-se na porção externa da dura-máter, de ambos os lados da pituitária, no osso basoesfenóide. Seios transversos, denominados de seios intercavernosos, conectam ambos os lados do seio cavernoso, formando um anel venoso circular ao redor da pituitária (Dyce et al. 1990, Zguigal \& Ghoshal 1991, King 1994). O seio cavernoso recebe sangue do sistema nervoso central e sangue de veias dos tecidos moles da cabeça como face, órbita, cavidade nasal e maxila. As veias do seio cavernoso são desprovidas de válvulas de forma que o fluxo sanguíneo pode fluir para ambos os sentidos (King 1994). Desse modo, o sangue venoso proveniente dos tecidos moles da cabeça, incluindo os da cavidade nasal, pode fluir no interior dos seios cavernosos e intercavernosos e em suas ramificações. Esse mecanismo tem a função de resfriar o sangue da rete mirabile epidural rostral antes que ele chegue ao sistema nervoso central (Zguigal \& Ghoshal 1991, King 1994). Acredita-se que essa dinâmica vascular venosa complexa torne essa região susceptível à deposição embólica de bactérias oriundas de outros sítios primários de infecção (Collet \& Bath 1994).
Baseado nos aspectos fisiológicos e anatômicos da circulação sangǘnea que circunda a pituitária tem sido sugerido que a disseminação bacteriana a partir de outros focos de infecção distantes, tais como mastites e artrites, aconteça através da circulação arterial até a rete mirabile epidural rostral. Adicionalmente, acredita-se que a disseminação bacteriana a partir dos tecidos moles da cabeça, como nos casos de rinite, ocorra através da circulação venosa até o seio cavernoso (Perdrizet \& Dinsmore 1986). O complexo vascular composto pela rete mirabile epidural rostral e pelo seio cavernoso é formado por artérias e veias de ambos os plexos, respectivamente. Os seios cavernosos de ambos os lados da pituitária formam estruturas plexiformes que se misturam à rete mirabile epidural rostral, constituindo-se de vários canais venosos de paredes finas, localizados entre as artérias e compartilhando a túnica adventícia com essas artérias ou formando grandes veias que rodeiam os ramos arteriais (Zguigal \& Ghoshal 1991). A disposição desse complexo arteriovenoso torna a região susceptível à deposição de bactérias veiculadas pela circulação venosa ou arterial e à formação de abscessos que afetam o complexo vascular e/ou a pituitária e o sistema nervoso adjacente.

Na SAP, a localização do abscesso pode ser variável, envolvendo inicialmente o complexo vascular e/ou a pituitária e posteriormente atingindo o encéfalo. Evidências de invasão do encéfalo por bactérias, nos casos observados neste surto e nos surtos anteriormente descritos (Paredes et al. 1996, Fernandes et al. 2000), incluem o envolvimento das meninges do cérebro e cerebelo e parênquima cerebral. Pode ocorrer, também, disseminação bacteriana a partir do abscesso pituitário para outros órgãos, principalmente os pulmões (Moriwaki et al. 1973, Paredes et al. 1996), como foi observado em um dos bezerros deste relato.

$\mathrm{O}$ diagnóstico da SAP associada à rinite traumática pelo uso da tabuleta nasal deve ser baseado nos dados epidemiológicos, nos sinais clínicos, nos achados de necropsia, nas lesões histopatológicas e no isolamento do agente etiológico (em geral A. pyogenes). Nos casos de SAP observam-se graus variáveis de envolvimento de pares de nervos cranianos (Perdrizet \& Dinsmore 1986). Esse fato, aliado ao histórico de uso da tabuleta nasal, auxilia no diagnóstico clínico e no diagnóstico diferencial com outras doenças que afetam o sistema nervoso central de bezerros e que ocorrem em surtos. O diagnóstico definitivo usualmente é realizado através da necropsia de um animal afetado em que é constatada a presença de um abscesso que normalmente ocupa toda a área da sela túrcica. É interessante notar que a presença de lesão traumática no septo nasal causada pela colocação da tabuleta plástica para desmame foi um achado infreqüente nos bezerros deste estudo. Na maior parte dos animais, não foi encontrada a porta de entrada para a bactéria piogênica de modo que o histórico do uso de tabuleta nasal foi decisivo para a pesquisa diagnóstica dessa condição.

Os sinais clínicos observados na SAP não são específicos e podem ser comuns a várias enfermidades, de diferentes etiologias, que afetam o sistema nervoso central de bovinos jovens. $\mathrm{O}$ diagnóstico diferencial deve incluir, do ponto de 
vista clínico, enfermidades infecciosas causadas por vírus como a raiva e a meningoencefalite por herpesvírus bovino 5 (BHV-5), intoxicação por chumbo e polioencefalomalácia associada ao excesso de enxofre ou deficiência de tiamina. Doenças que ocorrem de forma isolada, como meningite por Escherichia coli, abscessos cerebrais e listeriose, devem ser, também, incluídas no diagnóstico diferencial da SAP.

Uma das principais doenças a ser considerada no diagnóstico diferencial é a meningoencefalite por herpesvírus bovino tipo $5 \mathrm{em}$ bezerros. Essa enfermidade, assim como a SAP, ocorre em surtos e geralmente afeta animais jovens. No Rio Grande do Sul, surtos dessa enfermidade ocorrem em bezerros de 14 dias a 3 meses ou em animais de 6 a 7 meses recentemente desmamados. Esta doença pode ocorrer de forma esporádica ou sob a forma de surtos, afetando de 3 a $30 \%$ dos bezerros, sendo que em alguns surtos está associada a condições estressantes tais como o desmame. De forma semelhante, casos de SAP ocorrem, também, após o desmame. Entretanto, a SAP usualmente está associada a um histórico de traumatismo no septo nasal como no caso do emprego da tabuleta nasal. Clinicamente, ambas enfermidades apresentam sinais clínicos semelhantes tais como depressão, febre, disfagia, andar em círculos, ataxia, cegueira, sialorréia e flacidez da língua. Na meningoencefalite por herpesvírus o curso clínico pode, também, ser mais prolongado chegando até 15 dias. Entretanto, na infecção por herpesvírus bovino tipo 5, as lesões macroscópicas e microscópicas diferem bastante das lesões abscedativas observadas na SAP e são facilmente diferenciadas uma da outra. Na meningoencefalite por herpesvírus bovino tipo 5, observam-se, em parte dos casos, lesões macroscópicas caracterizadas por áreas de malácia no córtex cerebral e, microscopicamente, meningoencefalite nãosupurativa (Sanches et al. 2000, Riet-Correa et al. 2001). O diagnóstico definitivo dessa enfermidade deve ser realizado através do isolamento e identificação do vírus.

A raiva dos bovinos transmitida por morcegos pode ocorrer em surtos ou em casos esporádicos e deve ser incluída no diagnóstico diferencial da SAP. Entretanto, essa enfermidade viral pode afetar animais de várias espécies, idades e categorias dentro de um mesmo rebanho. Clinicamente, é caracterizada por incoordenação motora progressiva e perda da sensibilidade e paralisia, principalmente dos membros pélvicos. Não são observadas alterações macroscópicas e na histologia observa-se meningoencefalite não-purulenta associada a corpúsculos de inclusão intracitoplasmáticos. Para que o diagnóstico de raiva seja oficialmente reconhecido pelos órgãos governamentais do país deve haver a confirmação da etiologia da enfermidade através do exame do sistema nervoso pela imunofluorescência e/ou inoculação em camundongos (Sanches et al. 2000).

A intoxicação por chumbo afeta animais de qualquer idade, porém bezerros são mais afetados devido à tendência para lamber e morder objetos por curiosidade (Driemeier \& Loretti, 2001a). Entretanto, na maioria dos casos a toxicose ocorre de forma aguda ou subaguda e geralmente não há lesões macroscópicas e microscópicas específicas. A confirmação do diagnóstico deve ser feita através da dosagem des- se mineral no rim e fígado (Summers et al. 1995). O histórico de acesso inadvertido a fontes de chumbo p. ex., tintas e baterias também auxilia no diagnóstico.

A polioencefalomalácia associada ao excesso de enxofre na alimentação ou deficiência de tiamina pode ocorrer em animais de qualquer idade. Entretanto, grande parte dos casos dessa doença tem sido observada em animais entre $12 \mathrm{e}$ 18 meses. As alterações macroscópicas observadas diferem das observadas na SAP. Nos casos de polioencefalomalácia são observados tumefação e amarelecimento externo do encéfalo. As circunvoluções cerebrais apresentam-se achatadas e levemente amolecidas. Nos casos com evolução de vários dias, o cérebro apresenta edema acentuado, com deslocamento caudal e herniação do cerebelo através do forâmen magno. Ao corte observam-se áreas amareladas na substância cinzenta e, em alguns casos, hemorragia e malácia no tálamo e mesencéfalo. Histologicamente observa-se necrose laminar cortical. O diagnóstico é realizado com base nas lesões macro e microscópicas, na história clínica, em alguns casos na resposta favorável ao tratamento com tiamina e na autofluorescência de cortes transversais de cérebro quando expostos à luz ultravioleta (Lemos 1998, Driemeier \& Loretti, 2001b).

Listeriose, meningite bacteriana e abscessos cerebrais geralmente ocorrem de forma isolada, podendo apresentar sinais clínicos semelhantes aos da SAP. Entretanto, as lesões macroscópicas e/ou microscópicas são características em cada uma dessas enfermidades. O diagnóstico definitivo é feito através da avaliação das lesões macro e microscópicas e cultura bacteriana.

O tratamento recomendado para a SAP inclui antibioticoterapia de amplo espectro. No entanto, os resultados desse tratamento são limitados. Mesmo que os animais sobrevivam, podem ocorrer seqüelas neurológicas (Fernandes et al. 2000). Como medida profilática deve-se realizar a colocação de tabuleta para desmame interrompido com os cuidados higiênicos necessários. A ocorrência de SAP em bovinos foi rapidamente reduzida quando o septo nasal foi desinfectado antes da colocação do dispositivo nasal e quando antibióticos foram administrados profilaticamente aos animais (Moriwaki et al. 1973). O polimento das porções desse dispositivo que entram em contato com o tabique nasal pode também diminuir os efeitos traumáticos dessas tabuletas sobre a cavidade nasal.

\section{REFERÊNCIAS}

Collet M.G. \& Bath G.F. 1994. Actinomyces pyogenes infections, p. 1406-1415. In: Coetzer J. A. W., Thomson G. R. \& Tustin R. C. (ed.) Infectious Diseases of Livestock with Special Reference to Southern Africa. Vol. 2. Oxford University Press, Cape Town. 1605 p.

De Lahunta A. 1983. Veterinary Neuroanatomy and Clinical Neurology. W.B. Saunders Company, Philadelphia. 471 p.

Driemeier D. \& Loretti A.P. 2001a. Intoxicação por chumbo em bovinos. Anais $X$ Encontro Nacional de Patologia Veterinária (ENAPAVE), Pirassununga, SP, p. 244-245 (Texto completo).

Driemeier, D. \& Loretti, A.P. 2001b. Intoxicação por enxofre (polioencefalomalacia). Anais X Encontro Nacional de Patologia Veterinária (ENAPAVE), Pirassununga, SP, p. 245-246 (Texto completo). 
Dyce K.M., Sack W.O. \& Wensing C.J.G. 1990. Tratado de Anatomia Veterinária. Guanabara Koogan, Rio de Janeiro. 567 p.

Fernandes C.G., Schild A.L., Riet-Correa F., Bailardi C.E.G. \& Stigger A.L. 2000. Pituitary abscess in young calves associated with the use of a controlled suckling device. J. Vet. Diagn. Invest. 12:70-71.

King A.S. 1994. Physiological and Clinical Anatomy of the Domestic Mammals. Vol. 1. Oxford University Press, Oxford. 325p.

Lemos, R.A.A. 1998. Principais Enfermidades de Bovinos de Corte do Mato Grosso do Sul. Depto Medicina Veterinária, Universidade Federal de Mato Grosso do Sul, Campo Grande. 536p.

Mayhew I.G. 1989. Large Animal Neurology. A Handbook for Veterinary Clinicians. Lea \& Febiger, Philadelphia. 380p.

Moriwaki M., Watase H., Fukumoto M. \& Hayashi S. 1973. Exophtalmos due to rete mirabile abscess caused by infection with Corynebacterium pyogenes in cattle. Natl Inst. Anim. HIth Quart. 13:14-22.

Paredes E., Espinoza A., Canal A.M., Zamora J. \& Cubillos V. 1996. Descripcion de un brote de abscesos subhipofisiarios en terneros hereford. Anais XV Congresso Panam. Ciência Veterinária (PANVET), Campo Grande, MS, p. 162. (Resumo)

Perdrizet J.A. \& Dinsmore P. 1986. Pituitary abscess syndrome. Cont. Educ. 8:311-318.

Radostits O.M., Blood D.C., Gay C.C. \& Hinchcliff K.W. 2000. Veterinary
Medicine: a textbook of the diseases of cattle, sheep, pigs, goats and horses. Baillière Tindall, London. 1877 p.

Reilly L., Habecker P., Beech J., Johnston J., Sweeney C. \& Hamir A. 1994. Pituitary abscess and basilar empyema in 4 horses. Equine Vet. J. 26:424426.

Riet-Correa F., Schild A.L., Méndez M.C. \& Lemos R.A.A. 2001. Doenças de Ruminantes e Eqüinos. Vol. 1. Varela, São Paulo. 425p.

Rosa N.A. \& Real C.M. 1976-7. Desmame interrompido. Novo método para aumentar a fertilidade do rebanho bovino. Arq. Fac. Vet. UFRGS 4-5:74-77.

Sanches A.W.D., Langohr I.M., Stigger A.L. \& Barros C.S.L. 2000. Doenças do sistema nervoso central em bovinos no Sul do Brasil. Pesq. Vet. Bras. 20:113118.

Schild A.L., Riet-Correa F., Ferreira J.L.M., Méndez M.C. \& Fernandes C. G. 1996. Boletim do Laboratório Regional de Diagnóstico, UFPel. Ed. Gráfica Universitária, Pelotas. 108 p.

Smith M.O. 2002. Diseases of the nervous system, p.837-1018. In: Smith B. P (ed.) Large Animal Internal Medicine. 4th ed. Mosby, St. Louis. 1375p.

Summers B.A., Cummings J.F. \& DeLahunta A. 1995. Veterinary Neuropathology. Mosby, St. Louis. 527p.

Zguigal H. \& Ghoshal N.G. 1991. Gross and histologic study of the rostral epidural rete mirabile and the cavernous sinus in one-humped camels. Am. J. Vet. Res. 52:1173-1177. 